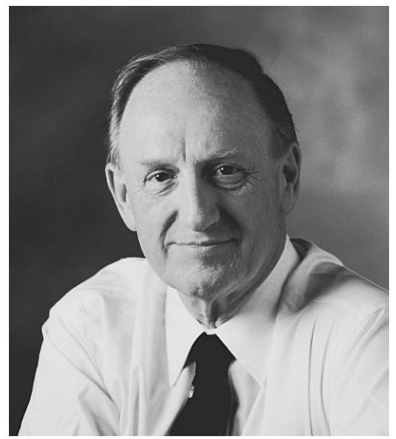

\section{To Accept or Not to Accept: That Is the Editorial Question}

The final outcome of the review and editorial process is a decision to either "accept" the manuscript or "not to accept" the manuscript. I use those two terms on purpose rather than the more common pair of outcome terms of "accept" and "reject." When editors get together the question is usually asked: "What is your rejection rate?" as if that is somehow a measure of the quality of the journal-the more papers you reject the more stringent the selection process and hence the inferred higher quality of those that are accepted. I contend that that is not necessarily so. I further contend that the editor has a responsibility to persuade the authors to present their work in a style and form and with a content consistent with the standards of the journal.

Answering the question about "rejection rate" (nonacceptance) or acceptance rate is not quite as straightforward as it may seem if the editor has indeed accepted the responsibility that I stated above. So let us look at the outcome of our journal Optical Engineering.

To provide some concrete analysis I looked at the first 200 papers that I received as submissions to Optical Engineering this year. Table 1 gives the final outcome and current status of those 200 papers, together with percentage in each category. "Accepted" means that the paper was accepted after the review process. "Not accepted", means the final outcome of the review process, which could have involved more than one cycle of review. The term "closed" means that after trying to work with authors to revise their paper that revision was not forthcoming. A small number of papers are "withdrawn" by the authors for a variety of reasons. Finally in this table there are a number of papers still "in process.'

Let us focus for the moment on the papers that have actually gone through the process to completion, i.e., 160 papers. Table 2 recasts the appropriate information from Table 1 . There is very close to a 60:40 split between those accepted and those that didn't make it (i.e., the sum of the other three categories). You might well conclude that in the vernacular we had a $60 \%$ acceptance rate and a $40 \%$ rejection rate.

It is worthwhile to look a little more closely at these numbers.

\section{Pathway to Acceptance}

Final acceptance of a paper can occur in a number of ways. This outcome is, of course, a result of an editorial decision based on the review process. The 97 papers accepted that are listed in Tables 1 and 2 break down into a number of subcategories as shown in the upper half of Table 3. Some are accepted after the review process with no change or at least only minor editorial changes. Others require some significant revision before they can finally be accepted; sometimes those revisions are considered mandatory and a rereview is carried out. Finally, some papers that are not accepted after the original review process are resubmitted in considerably revised form, rereviewed, and then accepted.

Table 1 Outcomes and current status.

\begin{tabular}{lcr}
\hline \hline & Number & $\%$ \\
\hline Accepted & 97 & 48.5 \\
Not Accepted & 53 & 26.5 \\
Closed & 8 & 4.0 \\
Withdrawn & 2 & 1.0 \\
In Process & 40 & 20.0 \\
\cline { 2 - 2 } Total & 200 & $100 \%$ \\
\hline \hline
\end{tabular}

Table 2 Status of completed papers.

\begin{tabular}{lcr}
\hline \hline & Number & $\%$ \\
\hline Accepted & 97 & 60.6 \\
Not Accepted & 53 & 33.1 \\
Closed & 8 & 5.0 \\
Withdrawn & 2 & 1.3 \\
\cline { 2 - 2 } Total & 160 & $100 \%$ \\
\hline \hline
\end{tabular}


Table 3 Pathways to acceptance and non-acceptance.

\begin{tabular}{|c|c|c|}
\hline & Number & $\%$ \\
\hline Acceptance after Review & 23 & 14.4 \\
\hline Acceptance after Revision & 67 & 41.9 \\
\hline Acceptance after Revision and Rereview & 2 & 1.2 \\
\hline $\begin{array}{l}\text { Acceptance after Initial Non-Acceptance } \\
\text { and Resubmission }\end{array}$ & 5 & 3.1 \\
\hline Not Accepted after Review & 50 & 31.2 \\
\hline Not Accepted after Revision & 3 & 1.9 \\
\hline Withdrawn & 2 & 1.3 \\
\hline Closed & 8 & 5.0 \\
\hline Total & 160 & $100 \%$ \\
\hline
\end{tabular}

\section{Pathways to Non-Acceptance}

The lower half of Table 3 shows the various pathways that lead to non-acceptance. The largest percentage of these 63 papers (see Tables 1 and 2) result from an editorial decision after the review process. Sometimes that editorial decision includes the statement that "if you wish to submit a revised manuscript I will seek further reviews." This can result in a resubmission of the manuscript. The outcome of the rereview may lead to acceptance, as we saw in the upper half of the table, or lead to non-acceptance. During these processes some authors elect to withdraw their paper from consideration. Finally, if, after some interchange with authors whose papers are being revised, no revised manuscript is forthcoming, I will close the file.

\section{Statement of Outcomes}

In interpreting these data the extreme rejectionist would claim a rejection rate of $85.6 \%$, i.e., the acceptance rate is the $14.4 \%$ shown in the first line of Table 1 . The more moderate rejectionist would claim a rejection rate of $43.7 \%$, i.e., the acceptance rate is the sum of lines 1 and 2 of Table 3. My own editorial view is to talk about the success rate and state that we have an acceptance rate of $60.6 \%$ (see Table 2). I am very satisfied (proud) of that rate. It is a tribute to the review process, the proactive editorial stance, and the author's positive response to constructive reviews that lead to better manuscripts. In the end it really is the quality of the work reported in these papers and the attention to writing a good paper that describes that work and puts it in context that leads to success.

I assure you that the process does not lead to publishing marginal material. So to the reader who has got this far in my editorial, read the journal, it's worth it.

\section{Editor's Anecdote}

Here is a new "excuse" for not having prepared a review of a manuscript that I received in response to my routine inquiry.

"I have been out of for $2-1 / 2$ months and have recently returned. My graduate student put the envelope with manuscript in the 'junk' mail pile."

What can I say that is fit to print?

Brian J. Thompson Editor 